\title{
Geotechnical hazard maps - A tool for ground support rehabilitation forecasting in active underground mines
}

\author{
E Tasse Golder, United States \\ C Griffiths Golder, Canada \\ R Bewick Golder, Canada
}

\begin{abstract}
The combined effects of corrosion and mining-induced rock mass strain on ground support installed in underground mining environments can result in both safety concerns and economic risks. Degradation of the ground support can lead to potential rock falls, and the rehabilitation of ground support can result in unplanned costs and production schedule delays. Underground mining environments can expose ground support elements to a wide range of strain and corrosive conditions. While studies have been ongoing to understand the different corrosion mechanisms, and how these affect the life of the ground support, few efforts have been made to integrate corrosion rates (or life of ground support elements) and strain aspects into a forecasting tool, to provide for a more realistic estimate of quantity and frequency at which ground support would need to be replaced. This paper covers the development of a spatial and temporal geotechnical hazard map to support proactive replacement of ground support for an active underground mine, and details how: corrosion rates, and strain can be compiled to forecast the need of replacement of the installed ground support, and improve the reliability of critical production excavations. First, the relevant corrosion mechanisms impacting ground support elements are covered and a brief discussion of corrosion rate estimation is provided. The paper then discusses how excavation strain information should be integrated to forecast ground support lifespan and presents a methodology to produce a 3-dimentional map, that can be used as a tool for forecasting the ground support replacement due to corrosion and strain over the life of mine.
\end{abstract}

\section{Introduction}

With the increase in demand for metals, deep and mass mining methods are more common in the mining industry than previously (World Bank 2020). These methods allow for the exploitation of deep and lowgrade deposits that would not be economical to mine with other methods. The required underground development can sometimes exceed hundreds of kilometres of tunnels and mass excavations to access the orebody, mine, and transport the ore to surface. The longevity of these excavations must be considered as they must be functional for longer periods of time than is typically common and, in some instances more than 20 years.

The impact of both consumption and degradation of the installed ground support, and the safety concerns this raises along with economic risks represent important aspects to consider at early stages of mine planning cycle. Degradation of the installed ground support can lead to potential falls of ground, and the rehabilitation of ground support can result in unplanned costs and production schedule delays.

Underground mining environments can expose ground support elements to a wide range of strain and corrosive conditions. While studies have been ongoing to understand the different corrosion mechanisms and how these affect the life of the ground support (e.g., Preston et al. 2019; Roy et al. 2016; Hassel et al. 2004), few efforts have been made to integrate corrosion rates (or life of ground support elements) 
and strain aspects into a forecasting tool to provide a more realistic estimate of quantity and frequency at which ground support would need to be replaced.

This paper covers the development of a spatial and temporal geotechnical hazard map to forecast the proactive replacement of ground support for an underground mine. The paper details how corrosion rates, and strain can be compiled to forecast the ground support replacement cycle, and improve the reliability of critical production excavations. Firstly, context is provided related to the need for hazard maps relating to the ground support life cycle and covers the relevant corrosion mechanisms impacting ground support elements. The effect of strain induced ground support capacity consumption is also detailed. The paper then presents a methodology to produce a 3-dimensional map to visualize the outputs from the forecasting approach. Finally, this paper discusses how excavation strain and corrosion information should be integrated to forecast ground support life span and how a hazard map can be used as a tool for forecasting ground support replacement due to corrosion and strain for the life of mine.

\section{The need for a hazard map}

A hazard map constitutes a useful visualization tool to broadly identify hazard areas. In this paper, the primary focus is to forecast the need for ground support replacement over the duration of an excavation's life, and thus a temporal aspect associated with changing ground conditions as mining progresses along with degradation in ground support capacity over time are considered. Other considerations such as the identification of weak ground or adverse structural conditions that could lead to delays in development or production, are additional aspects that could be integrated into a hazard map.

When the cost of ground support reaches several millions of dollars, understanding and being able to schedule where and crucially when ground support will need to be replaced represents a valuable aspect for mining companies. Additionally, this tool can be used to identify areas with potential ground stability issues and provide an effective way to allocate resources for additional targeted investigations.

\subsection{Forecasting life of ground support}

The focus of the study is to present how corrosion and mining induced rock strain could affect the installed ground support and how a hazard map visualization tool could be used to forecast when and where the installed ground support will need to be replaced.

\subsection{Effect of corrosion on ground support}

Several studies have been completed to evaluate the impact of corrosion on the ground support's life (e.g., Dorion et al. 2009; 2015; Dorion \& Hadjigeorgiou 2014). As detailed in Preston et al. (2019), underground mines are often wet, warm, and humid places that can create the perfect conditions for corrosion to occur. Hassel et al. (2004) and Roy et al. (2016) describe corrosive environments as either aqueous (e.g., minerals in the host rock or ore body that could contribute to the acidification of the ground water) or atmospheric (e.g., high atmospheric temperatures and high relative humidity due to mining equipment). Aqueous corrosion is generally considered to be the cause of more aggressive corrosion on ground support in an underground environment. However, atmospheric corrosion can impact the life expectancy of surface support elements such as bolt plates, mesh, and straps.

\subsection{Effect of strain on ground support}

Stress induced ground deformations in certain mining environments (e.g., cave mining) will impact the capacity of the ground support. As mentioned in Martin et al. (2003), instability for practical engineering purposes is usually assessed by considering a ratio of stress (demand) to strength (capacity). When stress magnitudes reach the rock mass strength, yielding will occur. In weak and soft rock masses, this will result in large convergence displacements. Hoek (1999) published details of an analysis that showed that the ratio of the uniaxial compressive strength scm of the rock mass to the in-situ stress can be used as an indicator of potential tunnel squeezing problems. This relation was further investigated to be related with the percentage strain defined as $100 \times$ the ratio of tunnel closure to tunnel diameter. Hoek \& Marinos 
(2000) detail in their case study the relation between geotechnical issues expected for different strain ranges and how the support elements would be affected. This empirical relation provides as useful indication of potential squeezing and support requirements for excavations in weak ground.

In hard and strong rocks, the yielding will be relatively small if the depth of failure is limited and the bulking is well controlled (Martin et al. 2003). However, large deformation could still occur with large rock mass dilation and bulking. Additionally, failure displacements with release of high level of energy could potentially lead to strainburst events (i.e., dynamic stress induced spalling).

The change in stress due the undercut advance and cave loading over the mine life will affect the ground support elements in both hard and weak rocks. In weak rock mass, large displacements will have to be considered in the design and life of the ground support. In hard brittle rock, estimation of the maximum stress concentration and the depth of spalling failure will help to choose the appropriate ground support elements. Note that in this study, the impact of strain related dilation and dynamic burst events in strong brittle rock is not considered.

\section{Developing a hazard map forecasting tool}

Developing a hazard map and an associated proactive replacement of ground support forecasting tool requires incorporating selected pertinent data to populate a block model. A block model helps facilitate spatial visualization of the geotechnical data to provide a series of outputs that can present single variables or multiple variables. These variables are used to store values that allow for hazard analysis as well as temporal (i.e., time dependant variables such as a rate of corrosion or stress components) for the analysis of ground support consumption.

Examples of hazard variables that could be incorporated into the hazard map block model for the definition of the hazard areas are geology, strength to stress ratio incorporating peak stress values (and associated time stages), corrosion rates, development and production schedules. Additional variables such as RQD, proximity to faults, hydrogeological conditions and overbreak are not considered for this study but constitute examples of additional variables that could be incorporated.

An example of basic workflow for developing as hazard map is as follows (Figure 1).

A geotechnical hazard map was developed as part of this study for a generic extraction level of a block cave mine using generic data. The variables integrated in the model and associated assumptions are detailed in the following sections.

\subsection{Geotechnical domains}

The geotechnical domains were defined based on ground conditions (i.e., poor, fair, good) (Figure 2). The weak ground domain is characterized by a Geological Strength Index (GSI) of 20 and a rock mass strength $(\mathrm{scm})$ of $4 \mathrm{MPa}$, the fair ground domain is characterized with GSI of 55 and scm of $15 \mathrm{MPa}$ and the good ground is characterized with GSI of 75 and scm of $30 \mathrm{MPa}$. These geotechnical parameters were used as inputs in the block model. 


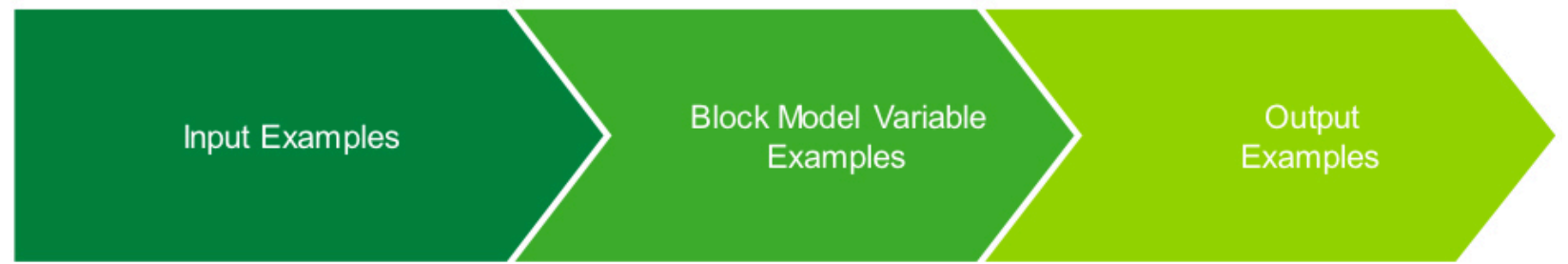

- $\mathrm{RQD} / \mathrm{Is} 50$

- Global Stress Model Outputs

- Strength (Intact \& Rock Mass)

- Structural Model

- Geological Model

- GSI

- Corrosion Rates

- Draw Schedule

- Development Schedule

- Water and Fragmentation Conditions

Figure 1 Example of hazard map block model workflow

- Strain Calculation

- Cable Degradation Rates

- Hazard Ratings; poor conditions encountered, weak ground, brittle ground, fault distance
- Spatial Maps of Forecasted Geotechnical Hazard

- Proactive Replacement of Ground Support

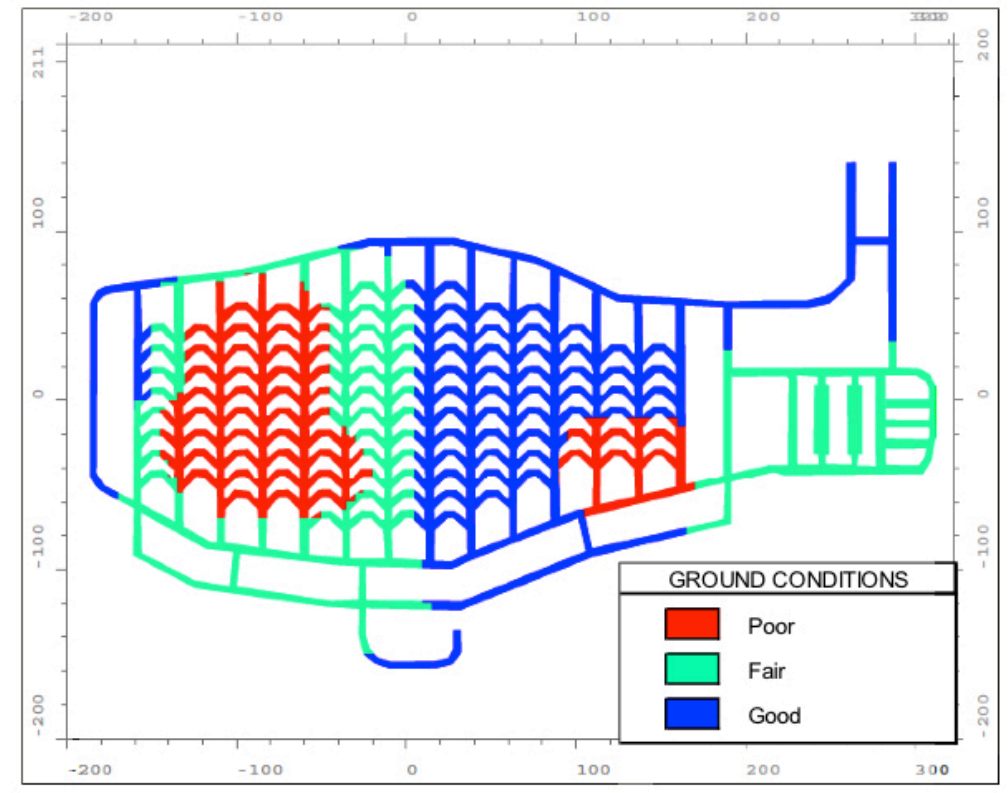

Figure 2 Generic extraction level with generic ground conditions 


\subsection{Global stress model}

Stress inputs were also a variable selected to capture temporal effects in this study. A stress path was simulated to represent the excavation loading over the life of the mine (i.e., assumed here to be 24 years). A temporal component was integrated by creating stress inputs every 6 months, from 2020 to 2044. A uniform peak stress value of $10 \mathrm{MPa}$, to represent in situ stress conditions, was assumed before mining. With the start of mining, and to represent the undercutting induced abutment load, the peak stress value was increased to $15 \mathrm{MPa}$, before decreasing to $5 \mathrm{MPa}$ associated with post undercut stress shadowing then continued to increase gradually to $20 \mathrm{MPa}$ representing a high peak cave load. The peak stress values for a given block within the block model for a given time step can be seen on Figure 3 and were used for the strain calculations.

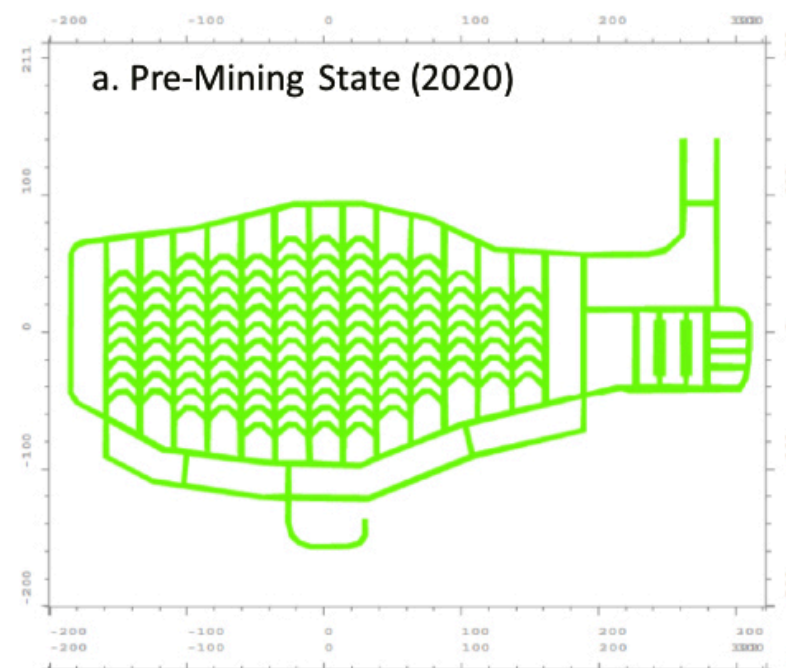

c. Post Mining State (2044)

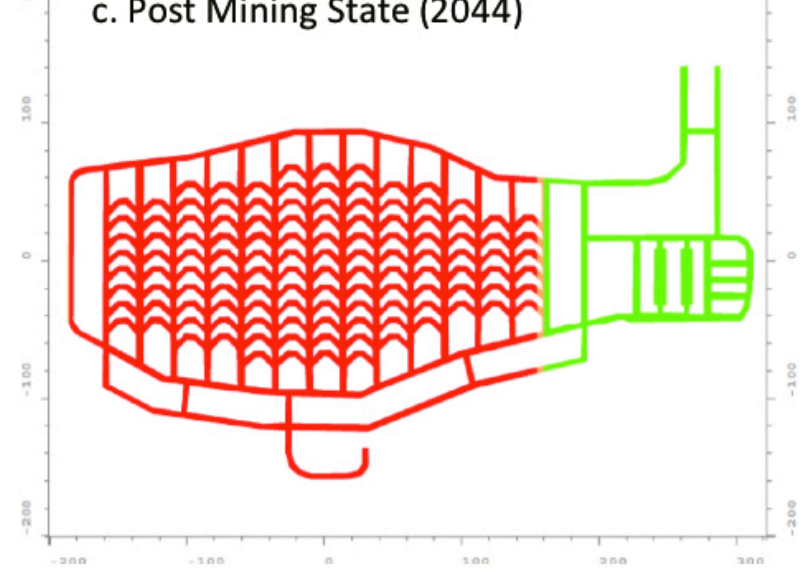

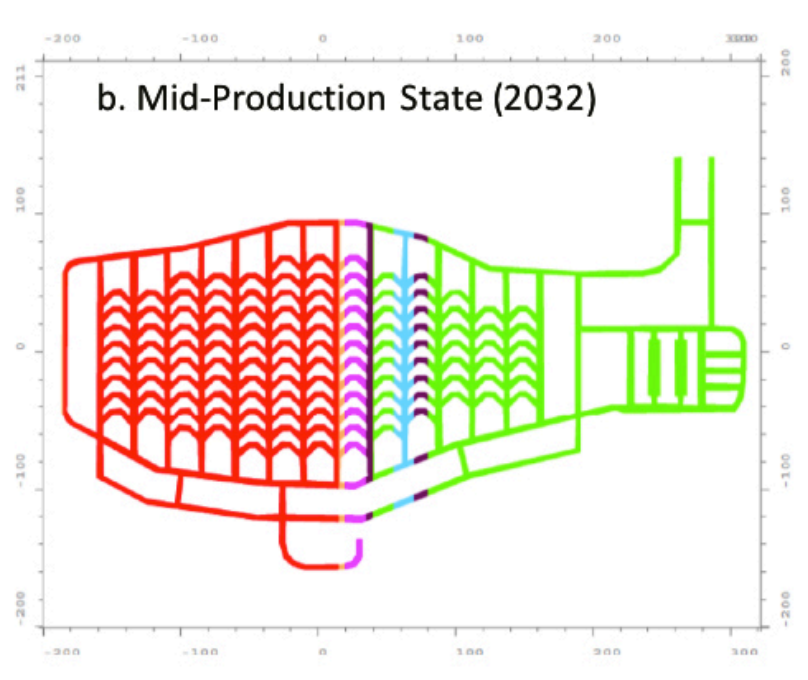

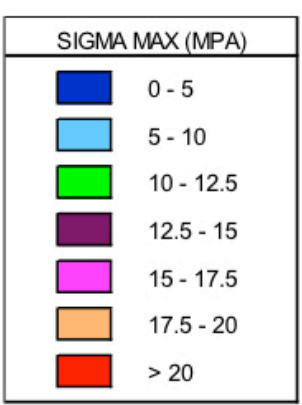

Figure 3 Generic extraction level with maximum stress. Shown at different stages of the mine life

\subsubsection{Strength to stress ratio}

As discussed earlier, the ratio of strength to stress is an indicator for areas where a combination of local stress conditions and weak or brittle ground could result in the potential for adverse tunnel convergence. This variable was therefore integrated into the generic block model. The strength to stress ratio estimate was estimated with the rock mass strength values defined for each geotechnical domain for each block within the block model (See Section 3.1).

\subsubsection{Strain}

Strain has been included as a temporal variable to estimate ground support capacity consumption over time (i.e., based on the change of stress conditions) to provide a forecast for the proactive replacement of ground support. 
Hoek and Marinos (2000) developed a relationship between tunnel strain and rock mass strength to stress ratio to be used as an indicator of potential squeezing problems (Figure 4). This relationship is for single tunnels in a virgin stress field and therefore has some limitations when applied to the caving environment where the stress-path evolves with time. While, this relation has limitations, it provides a conservative approach to estimate average tunnel strains to be used as a strain input to the block model.

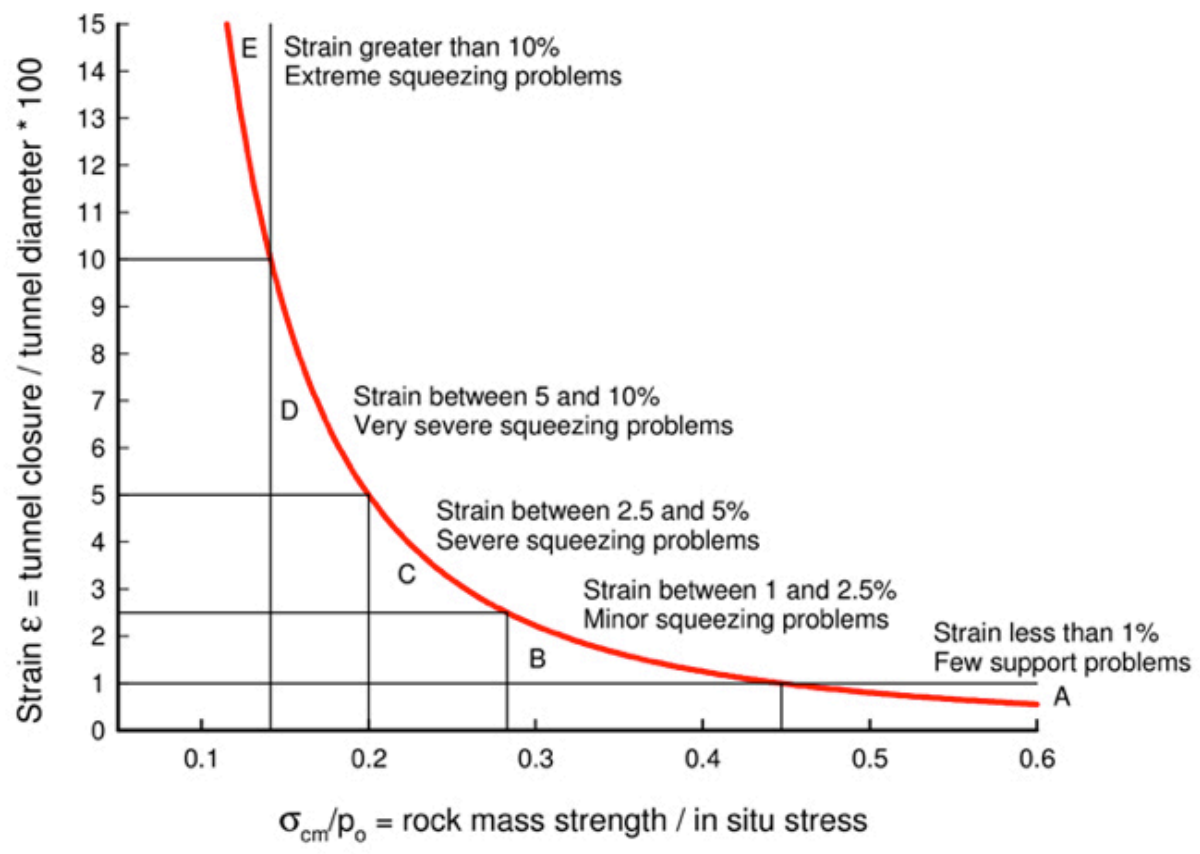

Figure 4 Strain and ratio of rock mass strength to in situ stress relationship curve Hoek \& Marinos (2000)

This estimate of strain uses the rock mass strength and the maximum stress value for a given time step. Strain was calculated in 6-month intervals from 2020 to 2044 to forecast the mine step at which excavation strain/displacement magnitudes are likely to meet or exceed established proactive replacement of ground support thresholds. For the purpose of these assessments a critical differential strain (strain at a given step minus initial strain) threshold of $2 \%$ is assumed to trigger the replacement of ground support. An increase in strain higher than $2 \%$ indicate severe to extreme squeezing problem for which rapid installation of support, secondary support and careful construction quality control will be required.

\subsection{Corrosion}

Corrosion of the ground support elements, by nature of the complex mechanisms, can range from being extremely localized to very uniform, with a wide range of corrosion rates possible. Thus, estimating absolute corrosion rates for any given area is challenging.

For the purpose of this study, corrosion is assumed to start immediately following excavation and subsequent installation of ground support and no consideration is given to potential encapsulation protection which could lower the rate of corrosion. Atmospheric corrosion and its impacts (e.g., bolt thread, teeth on nuts, etc.) is also not currently considered.

Corrosion rates are function of various hydrogeological, geochemical and geological factors. The rate of corrosion assumed for this study are generic only and will differ depending on site specific conditions. They are representative of different corrosion environments affected with different geologies, groundwater flow rates, groundwater $\mathrm{pH}$ values, relative air humidity and air temperature in the mine. These attributes could be cross referenced to delineate areas with different corrosion environments and the correlated data can then be input into a block model or simply overlain on mine plans to identify corrosion hazard zones (Figure 5). 
For this study, the effect of corrosion on ground support has been assessed by assuming a linear rate of corrosion applied to the installed ground support elements. The following linear corrosion rates were established (Roy et al. 2016):

- Low: $0.1 \mathrm{~mm} / \mathrm{year}$

- Moderate: $0.25 \mathrm{~mm} / \mathrm{year}$

- High: $0.4 \mathrm{~mm} / \mathrm{year}$

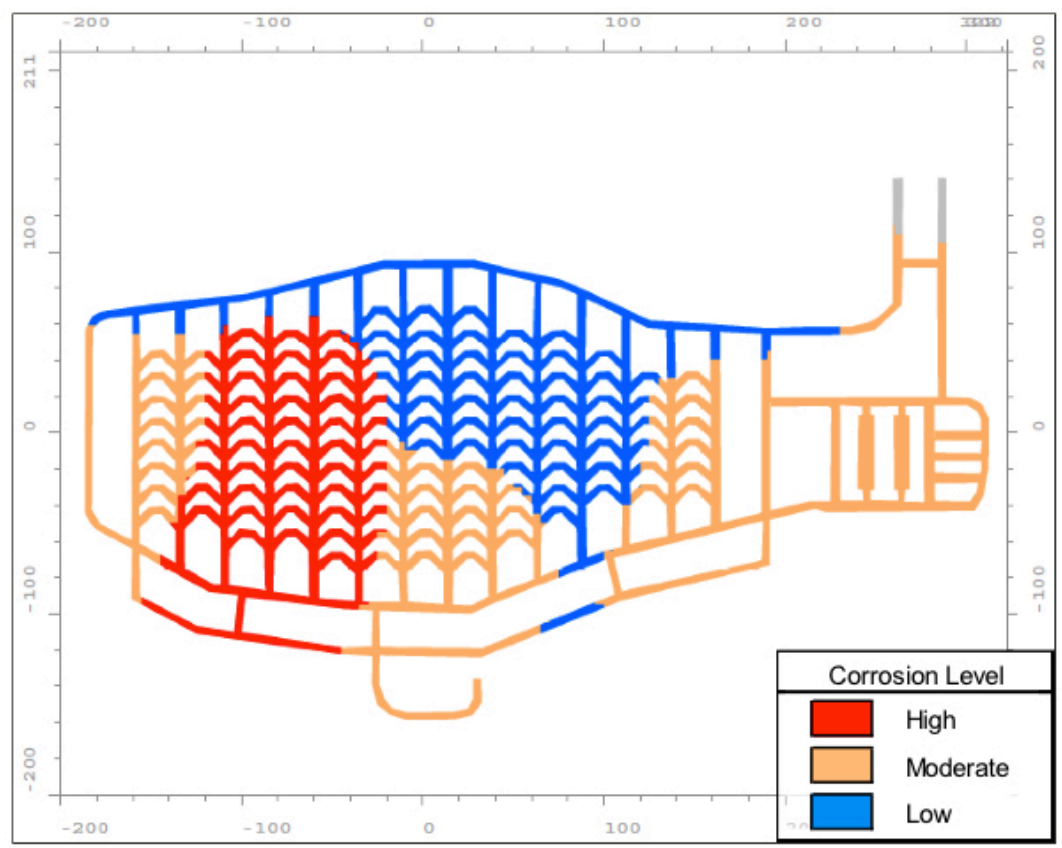

Figure 5 Generic extraction level with corrosion level zones

\section{$4 \quad$ Proactive replacement of ground support}

For the purposes of the evaluation of ground support replacement, assumptions need to be made regarding the installed ground support in any given location on the generic extraction level used as an example in this study. A variable was added to the block model detailing the installed support assuming one (1) cable bolt is installed in each block. This allows an estimate of the linear meters of extraction level that may require the ground support to be replaced. It was assumed that the ground support is installed immediately following excavation. For real world cases where as-built ground support information is available, more accurate estimates of quantities of ground support to be replaced can be made.

To determine the impact of the corrosion rate on the installed ground support, each block in the block model is coded with: the corrosion rate, the ground support installation date, the end date of production and the ground support element type (i.e., in this instance a $15.2 \mathrm{~mm}$ cable bolt). Based on this data the block model is then able to flag a given block for cable replacement when the cable diameter reaches a given threshold.

For this assessment, the replacement of ground support was assumed to be required when the cable diameter reaches $10.6 \mathrm{~mm}$ (i.e., $70 \%$ of original diameter). This reduction in cable cross sectional area is considered enough to reduce the capacity of the cable such that proactive replacement is recommended. In real assessments, once the loss of capacity is estimated based on corrosion rates, the expected convergence rate from numerical modelling or other measures of estimated service life should be cross referenced to determine the controlling factor for the ground support elements. 
Once a block is flagged for cable replacement, the cable diameter is replaced to its original value (i.e., $15.2 \mathrm{~mm}$ ) and the degradation rate is then re-applied. This allows for the flagging of areas in highly corrosive ground where multiple cycles of proactive replacement of ground support may be required for the operating life of the excavation.

In parallel to the corrosion effect, the differential strain (maximum strain minus initial strain) was also evaluated as such that when a threshold of $2 \%$ was reached for a time step, the cable was replaced, resetting the diameter to its original value (i.e., $15.2 \mathrm{~mm}$ ).

Based on the assumed rates of corrosion, differential strain and associated cable degradation, estimates of linear meters of the extraction level requiring a proactive replacement of ground support can be made using the variables added to the block model. Figures $6 \mathrm{a}$ and $6 \mathrm{~b}$ presents the estimated linear meters of the generic extraction level requiring cable bolt replacement over the operational life of the mine due to effects of corrosion and strain, respectively. It also possible to present the data as maps indicating the areas requiring cable to be replaced by year considering end date of excavation lives (Figure 7).

In this example, forecasted cable replacement due to the ground response to caving (i.e., strain) is expected in all the intersected poor ground from 2023 to 2038. Cable regarding corrosion is forecasted to start later in the mine life (i.e., 2030) and continue up to 2038. Excluding areas of weak ground, the rehabilitation of the ground support elements is mostly the result of moderate to high corrosion rates.
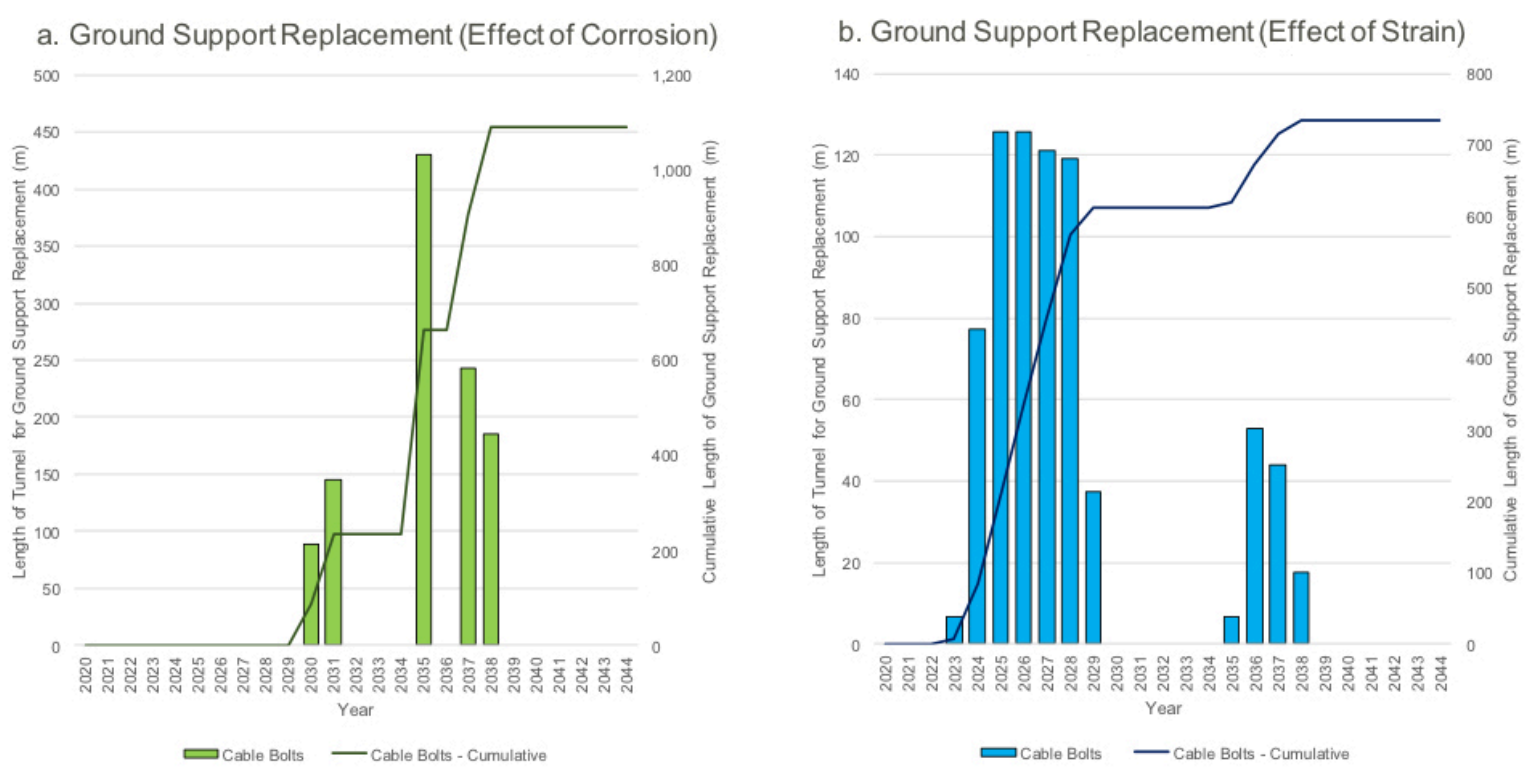

Figure 6 Linear estimates for cable bolts replacement. Due to corrosion (a) and due to strain (b) 

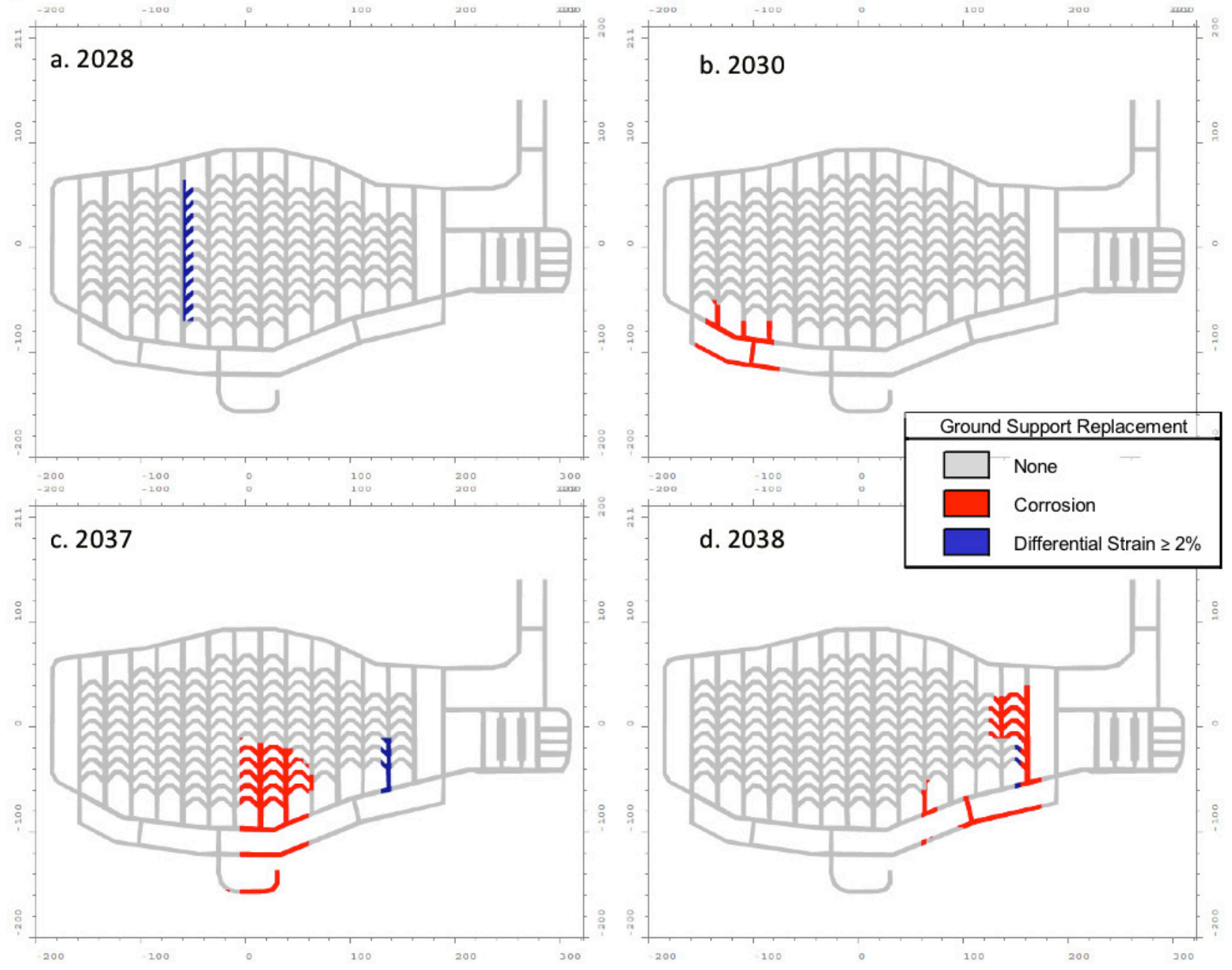

Figure 7 Example of bi-annual plots for the generic extraction level showing areas where ground support will need to be replaced

\section{$5 \quad$ Increasing forecasting confidence}

A hazard map in the context of this work is intended to be a real-time tool developed in such a way that allows for routine updating as new data becomes available. As new headings are developed and ground support inspections performed, a review of the inputs of the hazard map should be conducted to confirm its adequacy and increase the forecasting confidence. For example, poor ground should be updated in the block model where encountered (or not) and actual corrosion conditions updated.

While this tool has demonstrated to be a good starting point to estimate proactive ground support replacement, several improvements could be made. In this iteration, the coupled impact of strain on the corrosion rates are not considered and the corrosion rates are assumed to vary linearly. In the future it would be ideal to consider the acceleration of the corrosion rates due to loading and strain after the installation of the ground support elements. Another improvement would be to confirm the strain outputs and improve the empirical methodology with numerical modelling or available convergence measurements. Additionally, the strain outputs for the brittle ground obtained with the empirical methodology are potentially underestimated as bulking is not considered. 
In this study, the degradation due to the corrosion is assumed to start immediately after the installation of the ground support. However, there are available protection measures that would delay the start of the corrosion. As indicated in Preston et al. 2019, common examples in the industry are stainless steel, galvanization, full encapsulated support, coatings etc. The proper protection method should be selected based on the review of the corrosive environments encountered at the mine. Additionally, this work should be performed in collaboration with hydrogeologists to integrate detailed hydrogeological conditions (i.e., water inflow, pH). This to confirm that: 1) corrosion is applicable everywhere (i.e., dry areas should not be considered for corrosion) and 2) to confirm the corrosion rates.

\section{Conclusions}

The hazard map and associated ground support replacement forecasting tool is intended to be updated as often as the demand is needed. As shown in this study, the tool can help to forecast ground support replacement and aid in identification of areas with potential ground stability concerns as mining progresses. Used appropriately it can help to determine how quickly an area will require ground support replacement and help the mine to develop a schedule around it. Additionally, knowing in advance where and when replacement of ground support is needed will mitigate against unforeseen production downtime associated with a need to limit access while an excavation undergoes full ground support rehabilitation. However, as all models, the accuracy of the outputs and the confidence in the ground support replacement estimates need to be validated with actual site specific data. The methodology developed can be further improved up onto integrate more variables and refine the assumptions but the application of such a tool to date is promising and even in a preliminary phase of study or production can provide value to scheduling and cash flow models.

\section{References}

Dorion, JF, Hadjigeorgiou, J \& Ghali, E 2015, 'Quantifying losses in support capacity due to corrosion', Canadian Institute of Mining Journal, vol.6, no.3, pp.149-156.

Dorion, JF \& Hadjigeorgiou, J 2014, 'Corrosion considerations in design and operation of rock support systems', Mining Technology, vol.123, no.2, pp. 59-68.

Dorion, JF, Hadjigeorgiou \& J, Ghali, E 2009, 'Quantifying the rate of corrosion in selected underground mines', proceedings of the third CANUS Rock Mechanics Symposium, M. Diederichs and G Grasselli (eds), May 2009, Toronto, Canada.

Hassel, R, Villaescusa, E, Thompson, AG \& Kinsella, B 2004, 'Corrosion assessment of ground support systems', proceedings of the fifth International Symposium on Ground Support, Ground Support in Mining and Underground Construction, E Villaescusa and Y Potvin (eds), 28-30 September, Perth, Australia, Balkema, Rotterdam, pp. 529-544.

Hoek, E \& Marinos, P 2000, 'Predicting tunnel squeezing problems in weak heterogeneous rock masses', Tunnels and Tunnelling International.

Hoek, E 1999, 'Support for very weak rock associated with faults and shear zones', Rocksupport and reinforcement practice in mining, E Villaescusa, CR Windsor and AG Thompson (eds), Rotterdam: Balkema, pp. 19-32.

Martin, CD, Kaiser, PK \& Christiansson, R 2003, 'Stress, instability and design of underground excavations', International Journal of Rock Mechanics and Mining Sciences, vol. 40, pp. 1027-1047.

Preston, RP, Roy, J \& Bewick, RP 2019, 'Rusty bolts: planning for corrosion of ground support in underground mines', proceedings of the ninth International Symposium on Ground Support in Mining and Underground Construction, J Hadjigeorgiou and M Hudyma (eds), Australian Centre for Geomechanics, Perth, pp. 423-436.

Roy, J, Preston, R \& Bewick, RP 2016, 'Classification of aqueous corrosion in underground mines', Rock Mechanics and Rock Engineering, vol.49, 10.1007/s00603-016-0926-z.

World Bank Group 2020, Commodity Markets Outlook. April 2020. 